\title{
SIMULATION OF THE WRINKLING OF THIN HYPERELASTIC COMPOSITE STRIPS UNDER GLOBAL TENSILE LOADING
}

\author{
Marius M. Schasching ${ }^{1 *}$, Tilen Ceglar ${ }^{1}$, Melanie Todt $^{1}$ and Heinz E. Pettermann ${ }^{1}$ \\ ${ }^{1}$ Institute of Lightweight Design and Structural Biomechanics, TU Wien, Austria \\ *marius.schasching@tuwien.ac.at
}

Wrinkling of thin stretched laminated strips made of fiber reinforced elastomers is studied by means of the finite element method. The constitutive behavior of the individual plies is modeled using the Holzapfel-Gasser-Ogden (HGO) model [1] for which the material parameters are calibrated from experiments by employing a micromechanics based approach.

Linear eigenvalue analyses under consideration of a pre-loading are used to evaluate the critical tensile loads of the laminated strips as well as the mode shapes, i.e., the wrinkling patterns at the onset of buckling. Furthermore, a load-displacement analysis employing a moderately imperfect strip is used to study the influence of the layup on the evolution of the wrinkling pattern in the post-buckling regime in terms of wrinkling amplitude and the orientation of the wrinkles with respect to the material principal axes as exemplified in Figure 1. The obtained results can, e.g., serve as basis for designing structures with tunable surface behavior [2].

(i)

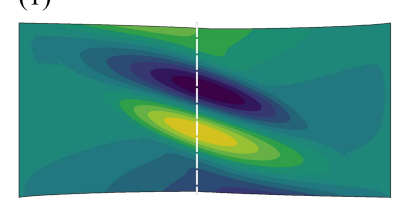

(2)

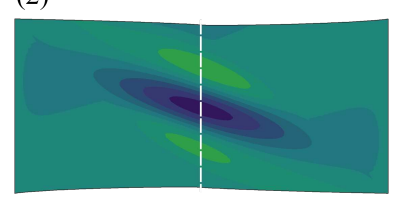

(3)

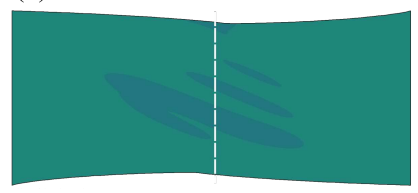

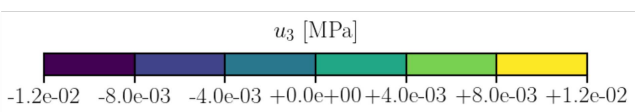

Figure 1: Evolution of the wrinkling pattern in the post buckling regime (right) of a single -45 ply under global tensile loading for applied overall streches of $\lambda=1.065,1.069$, and 1.140 in plot (1), (2), and (3), respectively.

\section{Acknowledgments}

The funding by the Polymer Competence Center Leoben GmbH (PCCL) within the COMETprogram by the Austrian Federal Ministry for Transport, Innovation, and Technology, the Austrian Federal Ministry of Digital and Economic Affairs, Österreichische Forschungsförderungsgesellschaft $\mathrm{mbH}$ (FFG), the Provinces of Styria, Lower Austria, and Upper Austria, is gratefully acknowledged.

\section{References}

[1] G. A. Holzapfel, T. C. Gasser, and R. W. Ogden (2000) A new constitutive framework for arterial wall mechanics and a comparative study of material models. Journal of Elasticity, 61, 148.

[2] Z. Li, Y. Zhai, Y. Wang, G. M. Wendland, X. Yin, and J. Xiao (2017) Harnessing surface wrinkling-racking patterns for tunable optical transmittance. Advanced Optical Materials, 5, 1700425. 